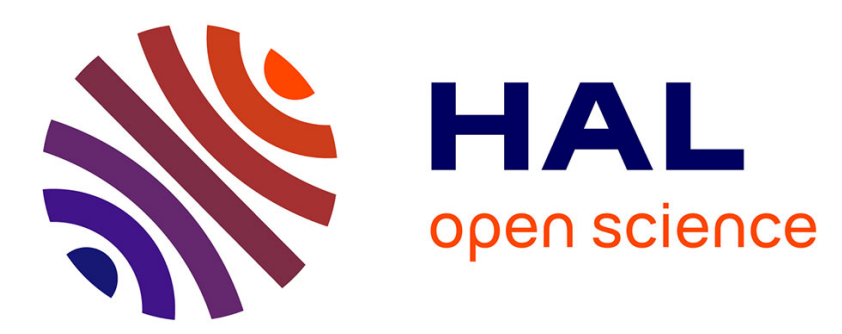

\title{
Thermodynamic desorption of oxygen in high Tc superconducting oxides
}

\author{
J.P. Burger, L. Lesueur, M. Nicolas, J.N. Daou, L. Dumoulin, P. Vajda
}

\section{To cite this version:}

J.P. Burger, L. Lesueur, M. Nicolas, J.N. Daou, L. Dumoulin, et al.. Thermodynamic desorption of oxygen in high Tc superconducting oxides. Journal de Physique, 1987, 48 (9), pp.1419-1422. 10.1051/jphys:019870048090141900 . jpa-00210571

\section{HAL Id: jpa-00210571 https://hal.science/jpa-00210571}

Submitted on 1 Jan 1987

HAL is a multi-disciplinary open access archive for the deposit and dissemination of scientific research documents, whether they are published or not. The documents may come from teaching and research institutions in France or abroad, or from public or private research centers.
L'archive ouverte pluridisciplinaire HAL, est destinée au dépôt et à la diffusion de documents scientifiques de niveau recherche, publiés ou non, émanant des établissements d'enseignement et de recherche français ou étrangers, des laboratoires publics ou privés. 


\author{
Classification \\ Physics Abstracts \\ 74.30E - 64.70K
}

\title{
Thermodynamic desorption of oxygen in high $\mathbf{T}_{c}$ superconducting oxides
}

\author{
J.P. Burger, L. Lesueur ${ }^{+}$, M. Nicolas, J.N. Daou, L. Dumoulin ${ }^{+}$and P. Vajda \\ Laboratoire Hydrogène et Défauts dans les Métaux, Bât. 350, 91405 Orsay, France \\ +C.S.N.S.M., Bât. 108, 91406 Orsay, France
}

(Reçu le 7 juillet 1987, accepté le 9 juillet 1987)

\begin{abstract}
Résumé.- Nous mesurons les pressions d'équilibre de l'oxygène desorbé par des oxydes supraconducteurs de formule $\mathrm{MBa}_{2} \mathrm{Cu}_{3} \mathrm{O}_{6+x}$. Nous en désuisons l'enthalphie de formation de l'oxygène $x$ en excès $(-0,7 \mathrm{eV} /$ atome $)$ ainsi que l'énergie d'interaction répulsive entre deux oxygènes $(0,11 \mathrm{eV})$. Nous observons également que l'oxygène désorbé est réabsorbé au-dessus de $600^{\circ} \mathrm{C}$, avec formation d'oxydes plus stables.
\end{abstract}

\begin{abstract}
We measure as a function of temperature and composition the equilibrium pressure of desorbed oxygen from superconducting oxides $\mathrm{MBa}_{2} \mathrm{Cu}_{3} \mathrm{O}_{6+x}(\mathrm{M}=\mathrm{Eu}, \mathrm{Y})$. Using the Lacher model we determine the enthalphy of formation of the excess oxygen $x(-0.7 \mathrm{eV} / \mathrm{atom})$ as well as the repulsive $\mathrm{O}-\mathrm{O}$ interaction energy $(0.11 \mathrm{eV})$. We also observe that there is a spontaneous reabsorption of the oxygen above about $600^{\circ} \mathrm{C}$ with formation of more stable oxides.
\end{abstract}

\section{Introduction.}

In this work, we present an experimental investigation of the thermodynamic desorption of oxygen in $\mathrm{Y} \mathrm{Ba}_{2} \mathrm{Cu}_{3}$ and $\mathrm{Eu} \mathrm{Ba}_{2} \mathrm{Cu}_{3} \mathrm{O}_{6+x}$. After the discovery of the new family of superconductors [1] it became immediately evident that air annealing at high temperatures was an important feature for the formation of these materials and that vacuum annealing destroyed the superconducting state [2]. This clearly shows the importance of the excess oxygen content $x$ involved in these absorption and desorption processes. For this reason it is important to measure quantitatively the equilibrium oxygen pressure $p(T, x)$ as a function of temperature and composition which may give information on the stability of this oxygen and on the sign and nature of the O-O interactions. For this we start with saturated samples $(x \simeq 1)$ and enclose them at room temperature under vacuum in a finite volume $V$ : subsequent heating permits us to follow the desorption of oxygen and to measure the equilibrium pressure $p$ as well as the change $\Delta x$ in composition. We prefer in fact to measure the desorption process rather than the absorption one because the latter phenomenon may be complicated by the necessary dissociation of the oxygen molecule at the surface.

1.1 MODEL OF LACHER [3].- The stability of the copper oxides is about the same as that of numerous hydrides, like the rare earth hybrides $\mathrm{REH}_{x}$ (the corresponding enthalpy of formation is for both systems in the $50-100 \mathrm{kcal} / \mathrm{mole} \mathrm{O}_{2}$ range). For this reason one expects similar equilibrium pressures for $\mathrm{O}_{2}$ and for $\mathrm{H}_{2}$ and one can then apply to $\mathrm{O}_{2}$ the model developed by Lacher [3] for the calculation of the equilibrium pressure in the hybrides.

In this model one admits that the energy of the oxygen takes the form :

$$
\begin{aligned}
U & =N \epsilon_{0}-1 / 2\left(N^{2} / N_{0}\right) z \epsilon_{\mathrm{i}}= \\
& -N_{0}\left[x \epsilon_{0}+x^{2}\left(z \epsilon_{\mathrm{i}}\right)\right]
\end{aligned}
$$


( $N$ is the number of oxygen atoms, $N_{0}$ is the number of empty sites available to the oxygen, $\epsilon_{0}$ is the binding energy of an isolated oxygen atom, $\epsilon_{\mathrm{i}}$ is the interaction energy between two oxygen atoms and $z$ is the oxygen coordination number).

The $p(T, x)$ equilibrium pressure is then obtained by equalizing the chemical potential of the oxygen inside the material with that of oxygen in the $\mathrm{O}_{2}$ gas. In this way one obtains

$$
\left(p / p_{0}\right)^{1 / 2}=\left[x /\left(x_{c}-x\right)\right] \mathrm{e}^{\Delta H / k T}
$$

$\left(x_{c}\right.$ is the maximum possible oxygen concentration, $\Delta H=\epsilon_{\mathrm{b}}-\epsilon_{0}-x\left(z \epsilon_{\mathrm{i}}\right)$ where $\epsilon_{\mathrm{b}}$ is the binding energy of oxygen in the $\mathrm{O}_{2}$ molecule, $p_{0}$ is a standard pressure). This formula is only valid for a repulsive interaction enrgy $\epsilon_{\mathrm{i}}$ (i.e. when $\epsilon_{\mathrm{i}}<0$ ). For attractive interactions and for $T<T_{\mathrm{c}} \simeq \epsilon_{\mathrm{i}}$, one expects a segregation of the oxygen into two phases (a low concentration $x_{1}$ phase and a high concentration $x_{\mathrm{h}}$ phase). Formula (1) remains valid for $T>T_{\mathrm{c}}$ but for $T<T_{\mathrm{c}}$ and $x_{\mathrm{i}}<x<x_{\mathrm{h}}$, one expects a constant plateau pressure, independent of $x$ and given by :

$$
\left(p / p_{0}\right)^{1 / 2}=\exp \left[\left(\epsilon_{\mathrm{b}}-\epsilon_{0}-\epsilon_{\mathrm{i}} / 2\right) / k T\right]
$$

Detailed investigation along this line on several metal-hydrogen system are given in references [4].

\section{Experimental.}

The samples were prepared from a mixture of pure $\mathrm{Y}_{2} \mathrm{O}_{3}, \mathrm{Eu}_{2} \mathrm{O}_{3}$ and $\mathrm{Ba} \mathrm{CO}_{3}$ (Johnson Matthey, Chemicals "Specpure") in atomic ratios of $\mathrm{Y}$ (or $\mathrm{Eu}$ )/ $\mathrm{Ba} / \mathrm{Cu}=1 / 2 / 3$. The mixed powders were pressed into pellets and sintered at $950^{\circ} \mathrm{C}$ in air during $24 \mathrm{~h}$. The resulting black compound was then ground, pressed and heated at $950^{\circ} \mathrm{C}$ in flowing oxygen ( 1 atm.) for 20 hours. The oven was allowed to cool down slowly to room-temperature. After a new grinding, a second annealing was carried out at $950^{\circ} \mathrm{C}$ during 12 hours always in flowing oxygen (1 atm.). The roomtemperature was reached very slowly from $950^{\circ} \mathrm{C}$.

The X-ray powder patterns show that both materials have at room temperature the sole orthorhombic structure with parameters in good agreement with the already published results [5].

The superconducting transition temperature obtained by resistivity measurements is $T_{\mathrm{c}}=93.5 \mathrm{~K}$ for the yttrium compound (with a $10-90 \%$ width of $0.7 \mathrm{~K})$. Similar results are obtained for the Eu compounds. The pressure $p(x, T)$ is measured for samples with a weight between 30 and $600 \mathrm{mg}$ enclosed in a volume of about $300 \mathrm{~cm}^{3}$. The pressure is recorded by a gauge (baratron); from the increase of pressure we deduce the oxygen loss $\Delta x$ through the relation $p V=n R T$ where $n$ is the number of desorbed $\mathrm{O}_{2}$ moles. We start the measurements at room temperature with an initial vacuum presure of $10^{-7}$ torr ; the increase of temperature is done at a rate of 1 degree/minute but the points in figure 1 are obtained after stabilizing the temperature during a period of about one hour.

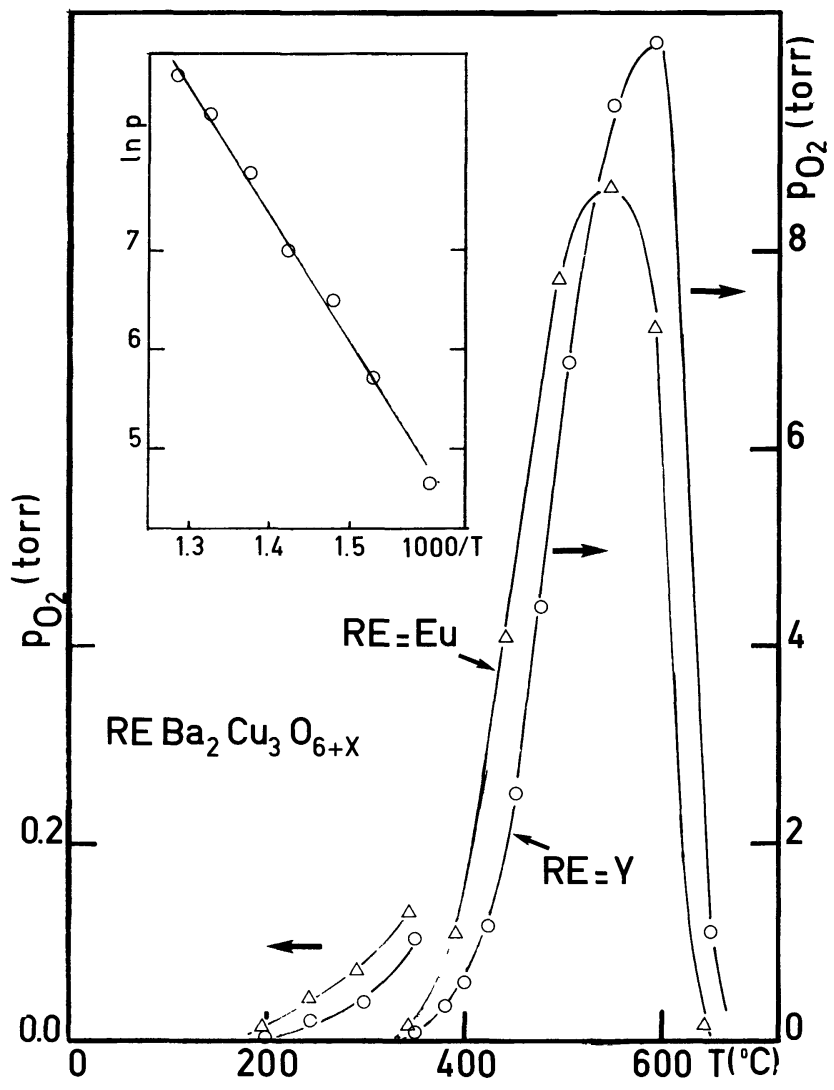

Fig.1.- Variation of the desorbed of oxygen with temperature. Note the reabsorption of the oxygen above $550^{\circ} \mathrm{C}$. In the insert we plot lnp as a function of $(1000 / T)$ in the range $570 \mathrm{~K}<T<$ $820 \mathrm{~K}$ : the slope is related to the enthalpy of formation $\Delta H$ ( $\ln p$ is expres in units of $10^{-3}$ torr).

\section{Results and discusion.}

\section{1.- INCREASE OF PRESSURE AS A FUNCTION OF} TEMPERATURE.- There is no appreciable desorption ( $p<10^{-3}$ torr) up to $200^{\circ} \mathrm{C}$ (Fig.1). The pressure increases quickly between $300^{\circ} \mathrm{C}$ and $520^{\circ} \mathrm{C}$ and it is in this temperature range that we will apply the Lacher model ; in fact above about $550^{\circ} \mathrm{C}$, we observe a dramatic reduction of the $\mathrm{O}_{2}$ pressure indicating that the sample reabsorbs its oxygen completely. An Xray investigation of the samples heated above $600^{\circ} \mathrm{C}$ shows that other phases have formed, among which there is the green phase $\mathrm{M}_{2} \mathrm{Ba} \mathrm{Cu} \mathrm{O}_{5}$ [4] ; this clearly indicates that the initial oxide has a low stability and transfoms into more stable phases for which there is nearly no further oxygen desorption up to $950^{\circ} \mathrm{C}$. It 
is nevertheless to be noted that the reabsorption did not occur in all investigated samples : if one chooses a small sample mass and a large volume, then the equilibrium pressure does not reach values as high as in figure 1 : the desorption continues then up tr $950^{\circ} \mathrm{C}$ with a marked increase of the slope $(\mathrm{d} p / \mathrm{d} T)$ near $820^{\circ} \mathrm{C}$; at this temperature, there occurs probably the orthorhombic-tetragonal transformation and the change of slope indicates that the oxygen is then less stable in the tetragonal phase.

The insert in figure 1 shows the variation of $\log$ $p$ with $1 / T$ (in the range $T<820 \mathrm{~K}$ ) from which one can deduce the enthalpy of formation $\Delta H$. The slope is $-0.55 \mathrm{eV}$ per 0 atom if one does not take into account the $\log \left(x / x_{0}-x\right)$ term which is related to the configurational entropy of the oxygen. In the tetragonal phase one has $x_{c}=2$ and the correction of the entropy term to $\Delta H$ is then small and nearly compensated by the variation of $p_{0}(T)$; but in the orthorhombic phase there are now two nonequivalent sites (each with $x_{c}=1$ ), the oxygen occupying for energy reasons mainly one of these sites ; with $x_{\mathrm{c}}=1$, we obtain a larger value for $|\Delta H|$; a reasonable compromise between these two extremes leads to $\Delta H=-0.70 \pm 0.15 \mathrm{eV}$. Such a binding energy is about two times smaller than the corresponding value in $\mathrm{Cu}$ oxides and it may explain qualitatively the trend for the formation of more stable oxides. It is also to be remarked that $\Delta H$ can be modified by the presence of a desorption energy barrier : the real $|\Delta H|$ is then somewhat smaller than the measured one.

\section{2.- OXYGEN LOSS $\Delta x$ AT CONSTANT TEMPERATU-} RE.- In order to follow an isotherm we start at a given equilibrium pressure and then we pump out quickly the corresponding oxygen (this takes only a few seconds) : after this we isolate again the sample in the closed volume and we wait for a new equilibrium. Figure 2 shows clearly that the new equilibrium pressure which is reached after about one hour is smaller than the initial one ; further pumping always leads to a new decrease of the equilibrium pressure. This means that there is no plateau pressure or that the $\mathrm{O}-\mathrm{O}$ interactions are either negligible or repulsive. The insert of figure 2 shows the evolution of $x$ after successive pumpings separated by equilibrium times of $75 \mathrm{~min}$ utes. It appears that the measured slope $(\mathrm{d} \ln p / \mathrm{d} x)$ $=24 \pm 5$ cannot be explained solely by the configurational entropy but is also involves the term $(\mathrm{d} \Delta H / \mathrm{d} x)$ resulting form $\mathrm{O}-\mathrm{O}$ interactions. A detailed analysis shows that the interaction energy is negative (i.e. repulsive) with a value $z \epsilon_{\mathbf{i}}=-0.45 \pm 0.15 \mathrm{eV}$ (or $\epsilon_{\mathrm{i}} \simeq-0.11 \mathrm{eV}$ ) in rough agreement with the previous data of Monod et al. [2]; the large uncertainty

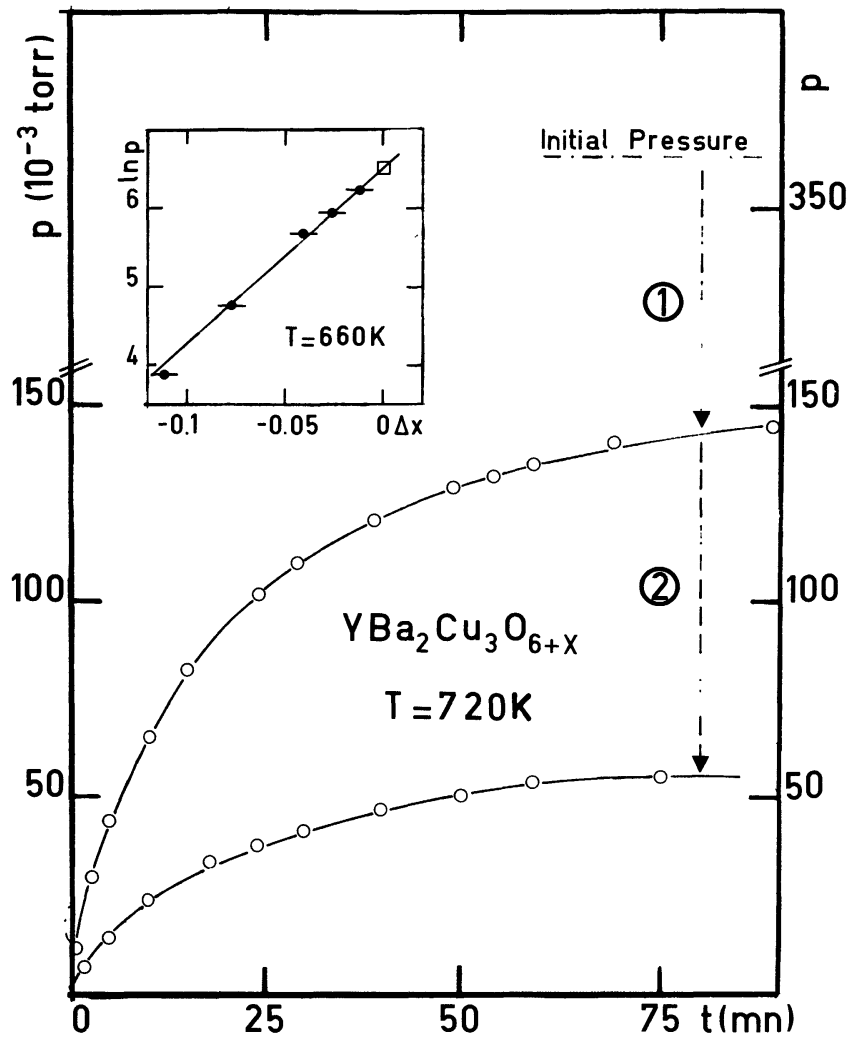

Fig.2.- Decrease of the equilibrium pressure (at constant temperature) with the variation of composition $\Delta x$ obtained by two successive quick pumpings of the oxygen. Equilibrium is reached after about one hour. The slope of the insert is related to the repulsive $\mathrm{O}-\mathrm{O}$ interactions $(\ln p$ is expressed in units of $10^{-3}$ torr).

is again related to possible variations of the parameter $x_{c}$. It is also to be noted that the absence of a plateau pressure is restricted to the domain $T<600^{\circ} \mathrm{C}$ and $6.5<x<7$.

At this level it is interesting also to discuss the possible origin of these repulsive interactions ; it may for instance correspond to true interactions related to charge transfer (ionic interactions) ; one can then wonder if the tetragonal-orthorhombic transition and the associated order-disorder transition and the associated order-disorder transition in the oxygen lattice are not related to these interactions. But it is also possible that the quadratic term in formula (1) reflects mainly non-linearities in the binding energy, for instance if $\epsilon_{0}$ is a function of $x$; the orthorhombictetragonal transformation must then be related to a different phenomenon : an electronic transition (like a Jahn-Teller transition) triggered by a lattice distortion due to different occupations of the two available oxygen sites can be a good candidate ; it is clear that the proposed Lacher model must incorporate some- 
how this tetragonal-orthorhombic transition in order to be complete.

Our main conclusion is that the energy of the $\mathrm{O}$ atoms in excess of the formula $\mathrm{M} \mathrm{Ba}_{3} \mathrm{Cu}_{3} \mathrm{O}_{6}$ is governed by two terms : a relatively small binding energy and an effective repulsive $\mathrm{O}-\mathrm{O}$ interaction ; but there remains to connect this phenomenological model with the electronic properties of the system i.e. with the metal-insulator transition and the associated lattice distortion and order-disorder transition of the oxygen atoms. It is interesting to note that all these problems also occur in the $\mathrm{REH}_{2+x}$ systems which are metallic for $x=0$ and insulator for $x=1$.

We would like to thank Ph. Monod and A. Revcolevschi for fruitful discussions.

\section{References}

[1] Bednorz, J., Muller, K.A., Z. Phys. $\mathbf{B 6 4}$ (1986), WU, M.K., et al. Phys. Rev. Lett. 58 (1987) 908,

Cava, R.J. et al., Phys. Rev. Lett. 58 (1987) 1676.

[2] Michel, M., Raveau, B., Rev. Chim. Miner. 21 (1984) 407, STROBEL, P., CAPPONI, J.J., Chaillout, C., Marezio, M., and Tholence, T.L., Nature $\mathbf{3 2 7}$ (1987) 306,

TARAscon, J.J., Kinnon, W.R., Greene, L.H., Hull, G.W. and Vogel, E.M., Phys. Rev. (to be published 1987). MONOD, P., RIBAULT, M., D'Yvoire, F., Jegoudez, J., Collin, G. and Revcolevschi, A., J. Phys. (1987).

[3] Lacher, J.R., Proc. Roy. Soc. A161 (1937) 625 .
[4] Alefeld, G., Phys. Status Solidi 32 (1967) 67. Mueller, W., Blackledge, J., Libowitz, G., Metal Hybrides (Academic Press New York) 1986.

WiCKE, E., Brodowsky, H., Hydrogen in Metals, Top Appl. Phys. (Springer Verlag) Vol. 11, 1978 , p. 29.

DAOU, J.N., LuCASSON, A., VAJDA, P., and Burger, J.P., J. Phys. F. 14 (1983) 2983.

[5] Kadowski, K., HUANG, Y.K., Van Sprang, M. and Menovsky, A.A., Physica 145B (1987) 1. Michel, C., and Raveau, B., J. Solid State Chem. 43 (1982) 73.

RaO, C.N., Ganguly, P., Raychaudhuri, A.K., Moham RaM, R.A., and Sreedhar, K., Nature 326 (1987). 